\title{
BREVES NOTAS SOBRE O ESTADO, A REGIÃO E O DESENVOLVIMENTO DESIGUAL
}

\author{
William E. Nunes Pereira ${ }^{1}$ \\ Ana Cristina dos Santos Morais ${ }^{2}$ \\ Francisco do O' de Lima Júnior ${ }^{3}$
}

\section{INTRODUÇÃO}

O sistema capitalista brasileiro, retardatário e atrasado, não promoveu um desenvolvimento equilibrado, provocando desigualdades regionais e sociais gravosas. A sociedade civil e o Estado necessitam harmonizar os valores sociais e os interesses econômicos, visando impulsionar o desenvolvimento econômico regional, erradicando a pobreza, reduzindo as desigualdades sociais regionais e tutelando outros valores, como o meio ambiente e as relações de consumo.

Historicamente, o desenvolvimento brasileiro foi marcado pela desigualdade social e regional. Mas não deve ficar reduzido ao bem-estar de alguns poucos grupos ou agentes. Para evitar a continuidade desse estado de coisas, a ação estatal é fundamental. Mas não uma ação qualquer e sim, uma ação deliberadamente estimuladora do desenvolvimento sustentável. Ação consolidada em políticas econômicas nacionais estruturadas juridicamente nos valores e princípios constitucionais, evitando assim medidas focais, limitadas e excludentes.

A intuito fundamental desse artigo é analisar sucintamente alguns pontos do processo de desenvolvimento desigual no Brasil e o papel da guerra fiscal na redução da desigualdade regional. A hipótese é que a guerra fiscal não contribui para a redução das desigualdades fiscais. A pesquisa histórico-dedutiva e a revisão bibliográfica se constituíram em atividades permanentes no decurso da elaboração desse paper. Um outro passo fundamental se constituiu em um levantamento de dados secundários que possibilitem a fundamentação das ideias desenvolvidas.

\section{O ESTADO NA CONCEPÇÃO MARXISTA}

Diversos autores procuraram, a partir da contribuição inicial de Marx e Engels, construir uma noção marxista para o Estado capitalista. Embora o debate sobre a hipotese de que Marx teria ou não criado uma teoria do Estado não tenha se concluido e persistam diversas visões ${ }^{4}$. Segundo David Harvey (2005), existia em Marx "a intenção de escrever um tratado especifico

\footnotetext{
1 Bacharel em Direito e Economia, Mestre em Economia, Doutor em Ciências Sociais (UFRN).

2 Bacharel, Mestre, Doutora e pós-doutoranda em economia (UFRN).

3 Bacharel, mestre e doutor em economia (UNICAMP).

${ }^{4}$ Sobre esse debate ver os trabalhos de: FARIAS, Flávio Bezerra. 0 Estado Capitalista Contemporâneo. São Paulo: Cortez, série Questões da Nossa Época, n. 73, 2000; LOJKINE, Jean. A análise marxista do Estado. IN: Espaço e Debates, número 01, ano 01, São Paulo, 1981; MILIBAND, Ralph. 0 Estado e a Sociedade Capitalista. Rio de Janeiro: Zahar, 1972; BOBBIO, Noberto. 0 marxismo e o Estado, Rio de Janeiro: Graal 1979. CARNOY, Martin. Estado e Teoria Política. São Paulo: Papirus, 1994.
} 
sobre o Estado" (HARVEY, 2005, p. 86), que não foi realizada, muito provavelmente, devido aos afazeres revolucionários e por uma morte precoce. Essas diversas visões enriquecem 0 paradigma marxista, pois enfatizam aspectos diferentes de um mesmo fenômeno. Essas versões se baseiam, normalmente, em alguns "fundamentos", por vezes "justificados" por passagens do escritos de Marx.

Três são os fundamentos básicos das diversas construções teóricas sobre o Estado na vertente marxista. O primeiro consiste no fato de que Marx considerar as condições materiais da sociedade a base de sua estrutura social e da consciência humana. Essa concepção se funda no próprio método marxista, o materialismo histórico-dialético, que revirando de ponta-cabeça 0 método hegeliano, define a infraestrutura de produção como determinante das estruturas sócioculturais, ou superestrutura. O segundo fundamento incide sobre a idéia de que o Estado não representa o bem-comum na sociedade, mas representa a expressão política da estrutura de classe dessa sociedade. Por fim, esse Estado Capitalista representa o braço repressivo da classe dominante na sociedade (CARNOY, 1994).

A literatura marxiana sobre o Estado, embora rica de indicações, não é conclusiva e ensejou entre os pensadores marxistas ampla, diversificada e questionada contribuição científica que, longe de consenso, apresentam vertentes diferenciadas.

Na concepção althusseriana, o Estado é uma máquina de reprodução social que habilita as classes dominantes a garantir sua dominação sobre a classe operária, e a ideologia assume papel importante nesse processo. Nas palavras de Althusser o "Estado é uma "maquina" de repressão que permite às classes dominantes...assegurar sua dominação sobre a classe operária para submetê-la ao processo de extorsão da mais-valia... " (ALTHUSSER, 1985, p 62). Essa visão permanece ainda hoje nos grupos mais radicais que não realizam uma leitura adequada de Marx.

No prefácio da "Contribuição para a Critica da Economia Política", de 1859, Marx aponta, sucintamente, o fulcro de sua concepção sobre o Estado capitalista. Esses apontamentos derivam, como o mesmo o asseverou, de suas pesquisas, que the permitiram algumas conclusões. Dentre essas conclusões, afirmou que as relações jurídicas do sistema capitalista e, entre elas as formas de Estado, não podem ser compreendidas por si mesmas. Portanto, necessitam para sua compreensão, da análise das condições materiais de sua existência, ou seja, para compreender-se toda a superestrutura criada e ampliada no capitalismo, é imperativo compreender-se o processo de produção social desse sistema ou, mais simplesmente, as relações sociais de produção. O próprio Marx ensejou que essa compreensão Ihe permitia o "fio condutor" de suas análises posteriores. Nas palavras de Marx: 
...na produção social da sua existência, os homens estabelecem relações determinadas, necessárias, independentes da sua vontade, relações de produção que correspondem a um determinado grau de desenvolvimento das forças produtivas materiais. $O$ conjunto destas relações de produção constitui a estrutura econômica da sociedade, a base concreta sobre a qual se eleva uma superestrutura jurídica e política e à qual correspondem determinadas formas de consciência social. 0 modo de produção da vida material condiciona o desenvolvimento da vida social, política e intelectual em geral (MARX, 1983, p.24).

Marx procura assim demonstrar que não é simplesmente a vontade dos homens que fornece ao Estado sua estrutura. As relações sociais de produção ou, em outras palavras, todas as relações que se estabelecem no âmbito do processo de produção dos meios e condições para a vida humana, são que geram a superestrutura ou o arcabouço jurídico, político, cultural, ideológico da sociedade humana. O Estado, como uma estrutura jurídica, política e ideológica, é, assim, um produto resultante do desenvolvimento das relações sociais de produção. Com essa reflexão, nega Marx a concepção hegeliana do Estado criador da sociedade civil.

Nas diversas obras marxianas aparecem referências ao Estado. A que mais se tornou popular entre os estudiosos marxistas do Estado consiste no Manifesto Comunista. Elaborada conjuntamente com Engels serviu e continua servindo de fundamentação para a linha mais ortodoxa do pensamento marxista. Nela encontramos uma assertiva marxista muito utilizada pela ortodoxia, que define que o poder executivo do Estado moderno não é mais do que um comitê para dirigir os negócios comuns de toda a burguesia (ENGELS, 1980).

Outra obra bastante utilizada para fundamentar as teorias marxistas do Estado é a "Origem da família, da propriedade privada e do Estado" de Engels, de 1884. Nela, Engels define o Estado capitalista como "um produto da sociedade numa certa fase do seu desenvolvimento". O Estado surge na sociedade e se afasta dela com a finalidade de intervir no conflito de classes. Essa intervenção não se dá com o intuito de arbitrar as diferenças entre as classes, mas sim de evitar que elas se destruam no conflito.

\section{Explicitamente, Engels diz que:}

O Estado não é, pois, de modo algum, um poder que se impôs à sociedade de fora para dentro; (...) É antes um produto da sociedade, quando esta chega a um determinado grau de desenvolvimento; é a confissão de que essa sociedade se enredou numa irremediável contradição com ela própria e está dividida por antagonismos irreconciliáveis que não consegue conjurar. Mas para que esses antagonismos, essas classes com interesses econômicos colidentes não se devorem e não consumam a sociedade numa luta estéril, faz-se necessário um poder colocado aparentemente por cima da sociedade, chamado a amortecer o choque e a mantê-lo dentro dos limites da 'ordem'. Este poder, nascido da sociedade, mas posto acima dela se distanciando cada vez mais, é o Estado (ENGELS, 1980, p. 135). 
Na conceituação de Engels devemos ressaltar a importância que o mesmo dá ao fato do Estado impor-se à sociedade, mas nascer dela própria, da incapacidade de conciliação entre as classes envolvidas em um conflito interno da sociedade. O Estado é o mecanismo criado pela própria sociedade para impedir sua própria destruição. Nessa pequena passagem do livro, Engels ensejou em alguns pensadores a visão de que o Estado é um instrumento de conciliação das classes, fato combatido por Lênin, como visão pequeno-burguesa e oportunista.

Dois traços característicos do Estado são apresentados por Engels. O primeiro consiste na reunião dos súditos do Estado de acordo com a divisão territorial. O segundo consiste na instituição de uma força pública. Essas características geram implicações das quais, a criação do imposto é uma das mais relevantes, pois "recaem" sobre a população, principalmente sobre os trabalhadores. A força pública garante a exeqüibilidade na cobrança dos impostos e mantém a pax romana, garantido o distanciamento do Estado da sociedade que o criou.

Em sua análise do Estado, Engels aponta a república democrática como a mais elevada forma de Estado, e que, nas condições de sua época, estava se tornando uma necessidade iniludível, perspectiva que, atualmente, tornou-se imperiosa. Da mesma forma, o sufrágio universal é apontado como índice de amadurecimento da classe operária. Essas duas concepções de Engels foram também 'deturpadas', segundo Lênin, gerando uma série de vertentes políticas do encaminhamento das lutas operárias, seja pelos acadêmicos, ou sindicatos, ou partidos. A deturpação caminha sempre no sentido de amortecer o espírito revolucionário da classe proletária, levando-a a acordos e uniões que não contribuem para a revolução no pensamento leninista. Em síntese, a idéia de Engels é que, o Estado é o resultado e a manifestação do antagonismo inconciliável das classes. Afinal, o Estado surge quando a divisão social do trabalho e a propriedade privada já se desenvolveram a tal ponto que o conflito de classe emerge e se apresenta de forma inconciliável.

Além da obra de Engels, o "Manifesto Comunista", como já mencionado, constitui-se em outra obra importante para o desenvolvimento das visões marxistas do Estado. Com base nessas obras e em fragmentos de outras, pode-se dizer que os fundamentos básicos que sustentam os constructos teóricos sobre o Estado na visão marxista são três. 0 primeiro fundamento consiste no fato de que Marx considera as condições materiais da sociedade a base de sua estrutura social e da consciência humana. Essa concepção se funda no próprio método marxista, o materialismo histórico-dialético, que revirando de ponta-cabeça o método hegeliano, define a infraestrutura de produção como determinante das estruturas sócio-culturais, ou 
superestrutura ${ }^{5}$. 0 segundo fundamento é a idéia de que o Estado não representa o bem-comum na sociedade, mas representa a expressão política da estrutura de classe dessa sociedade. Por fim, esse Estado Capitalista representa o braço repressivo da classe dominante na sociedade (CARNOY, 1994).

O debate marxista sobre o Estado inspira-se muito no Manifesto Comunista e na Origem da Família. No entanto, deve-se ressaltar que a análise do Estado, com base unicamente nesses textos, além de limitada, leva uma ortodoxia que nega o espírito evolutivo e revolucionário de Marx. Em diversas outras obras, a exemplo de 018 Brumário e Crítica ao Programa de Gotha, Marx realiza uma análise bem mais profunda do que seja o Estado capitalista. No Capital, obra de sua maturidade, Marx reconhece a possibilidade da classe trabalhadora "obrigar" o Estado capitalista, o comitê burguês, a conceder-lhes determinados benefícios, em prejuízo da classe capitalista. Esse poder da classe trabalhadora de obrigar o Estado a beneficiá-la, devia-se ao fato dos trabalhadores revoltarem-se, provocando a possibilidade de uma ruptura da ordem estabelecida. Para evitar tal ruptura, o Estado realizava algumas concessões.

A redução da jornada de trabalho se constituiu em uma dessas concessões. Marx mostra também que, o fato de o Estado se colocar parcialmente contra a classe capitalista, não implica uma ruptura total, muito menos, que o capital fique encurralado. As alternativas são criadas pelo capital para manter a continuidade das condições de obtenção de lucro. A citação abaixo evidencia a percepção de Marx sobre tal situação.

Assim que a revolta cada vez maior da classe operária obrigou o Estado a reduzir à força a jornada de trabalho, e a ditar, inicialmente às fábricas propriamente ditas, uma jornada normal de trabalho, a partir desse instante, portanto, em que se impossibilitou de uma vez por todas a produção crescente de mais-valia mediante o prolongamento da jornada de trabalho, o capital lançou-se com força total e plena consciência à produção de mais-valia relativa por meio do desenvolvimento acelerado do sistema de máquinas (MARX, 1988, p . 31). (grifo nosso).

A citação acima mostra bem como o conflito de classes interfere e pressiona o Estado a atuar em prol da classe trabalhadora. Da mesma forma, tanto o conflito de classes como 0 Estado interferem diretamente na produção do espaço, tornando-o resultado das relações de produção social. Essas interferências implicam transformações constantes no espaço urbano e na economia que implicam mudanças societais constantes.

${ }^{5} \mathrm{~A}$ ênfase sobre esse fundamento implicou no desenvolvimento do estruturalismo, nas suas mais diversas vertentes. 


\section{A REGIÃO, ENQUANTO CONCEITO QUE SE MATERIALIZA.}

A importância do conceito de região ascendeu abruptamente no pós segunda grande Guerra. Essa ascensão se deve em grande parte aos inúmeros conflitos políticos, econômicos e militares que, em meio aos 25 anos gloriosos do capitalismo, pululavam nos quatro quantos da terra. Diversas ciências se voltaram para a questão do espaço, do território, da região, etc. Não apenas os geógrafos, mas os economistas, os juristas, historiadores, dentre tantos.

Inicialmente deve-se esclarecer que nossa visão de espaço socialmente definido se assemelha ao conceito de região de Oliveira "que se fundamenta na especificidade da reprodução do capital, nas formas que o processo de acumulação assume, na estrutura de classes peculiar a essas formas..." (OLIVEIRA, 1985, p. 27). Por espaço socioprodutivo entendemos o lócus habitado pelo homem, ou seja, o espaço físico ocupado por ele cujas características naturais e sociais se transformam continuamente pela ação da natureza e pela ação humana. Ação humana em eterno conflito classista, consequência do processo de acumulação e reprodução do capital, e do processo de apropriação privado do produto criado neste espaço. Este espaço socioprodutivo não tende a respeitar as fronteiras territoriais prédefinidas institucionalmente, devido às relações que o mesmo tem com outros espaços.

No espaço social ocorre o desenvolvimento das atividades produtivas e não produtivas, que permitem a continuidade existencial do homem. A compreensão do desenvolvimento desta sociedade no espaço - região por exemplo - implica a compreensão do desenvolvimento das formas de produção capitalista que se estabelecem neste espaço. Desenvolvimento capitalista que implica não somente a produção de mercadorias, mas também a realização dessas através do processo de circulação. A estrutura e o desenvolvimento dos espaços sociais apresentam-se como uma consequência do processo de reprodução do capital, que é desigual e combinado, ${ }^{6}$ possibilitando-nos supor que as formas pelas quais o capital se reproduz em determinados momentos explique o desenvolvimento de uma região, unidade federativa, microrregião ou mesorregião como também o declínio das atividades outrora dinâmicas.

O processo de reprodução do capital transforma continuamente as relações produtivas entre os espaços econômicos. Transformações essas, que implicam em alterações na funcionalidade de cada espaço produtivo, devido às especificidades que cada fase do processo de reprodução do capital assume. Essas transformações impõem um ajustamento forçado aos

\footnotetext{
6 ...Segundo Oliveira (1985), o caráter desigual e combinado das leis de desenvolvimento do capitalismo podem ser vistas nas obras de Lenim - El Desarrollo del Capitalismo en Rusia, in Obras Completas, Tomo III ed. Cartago, Buenos Aires, 1957 - e na História da Revolução Russa, de León Trotsky publicada pela ed. Saga do Rio de Janeiro. Pág. 27
} 
espaços sociais, que podem implicar na desorganização de sua estrutura produtiva e, consequentemente, na imposição de um ônus aos segmentos socioprodutivos que não conseguem adaptar-se à nova fase de reprodução do capital. Este permanente reajustamento dos espaços produtivos às novas fases da reprodução do capital ocorre sob o comando do espaço social no qual se deu com maior intensidade o desenvolvimento das forças produtivas. Este reajustamento pode ser visto como uma propagação ou um aprofundamento das relações de produção capitalistas (GUIMARÃES NETO, 1989).

O espaço social em estudo torna-se determinado e determinante do aprofundamento das relações de produção. Determinado quando o seu desenvolvimento é uma consequência das relações que se estabelecem com os espaços de comando, e determinante quando assume a hegemonia de uma extensa área além do seu território institucionalmente definido.

A essa construção socioeconômica alie-se a dimensão jurídico-normativa da determinação do espaço regional. Nos debate sobre o conceito jurídico de região, destaca-se sempre a contribuição de Georg Jellinek. Para esse autor a região se constitui como uma formação política submetida ao poder do Estado, mas não integralmente incorporada. A região possui características semelhantes a de um Estado, mas não na sua forma integral. A região se constitui como um espaço dotada de existência política limitada e dependente. Para Jellinek, a região se diferencia tanto do Estado como dos Estados-membros de uma Federação. Por não ser um Estado, apenas constituindo-se como protoforma rudimentar de um Estado, a região é denominada, por Jellinek como um "fragmento" de Estado (BERCOVICI, 2003).

Bercovici nos mostra que a “(...) ideia de 'fragmento de Estado' é, constantemente, trazida ao debate jurídico sobre o conceito de região." (BERCOVICl, 2003, p. 69). No entanto, espanhóis e italianos majoritariamente rejeitam tal concepção, embora alguns pensadores a exemplo de Miguel Herrero de Minón (1985), continuam divulgando tal conceito. Independentemente do debate sobre o conceito de região na esfera jurídica, não se pode olvidar que as regiões brasileiras são criadas por lei. Considerando os interesses de grupos políticos econômicos que exerçam sua hegemonia no Estado, a configuração regional estará sempre dependente desses grupos em conflito com as oligarquias locais e os seus interesses políticos e econômicos. Basta-nos observar o redesenho regional do Brasil no Século XX para compreender as determinações institucionais de região e as imbricações entre as diversas esferas institucionais dentro da região juridicamente definida.

Em resumo, a concepção de região a ser utilizada une a institucionalização jurídica, via leis nacionais, com a concepção que o processo de reprodução do capital transforma incessantemente as relações econômicas e produtivas, alterando o espaço e exigindo novas 
determinações jurídicas das fronteiras para atender as exigências do processo de reprodução capitalistas e o resultado dos conflitos de classes emergidos via choques entre as oligarquias locais e nacionais.

Furtado sintetiza bem as constantes reconfigurações regionais, quando nos mostra que:

Como somos um país com fronteiras que se deslocam permanentemente dentro do próprio território, nosso conceito de região é necessariamente dinâmico. Mas essa consciência de unidade nacional, dentro de um espaço que se expande, coexiste com o senso de identidade que se definiu historicamente em cada região particular. A identidade do brasileiro tem raízes em sua inserção regional (...) (FURTADO, 1999, p. 47).

\section{O DESENVOLVIMENTO ECONÔMICO REGIONAL DESIGUAL NO BRASIL}

É consenso para a maior parte dos estudiosos, que o ano de 1930, é um ano que marca a mudança fundamental nos rumos da sociedade e da economia brasileira. A mudança do padrão de acumulação de capital assume caráter de revolução burguesa. A crise socioeconômica mundial de 1929, impôs bruscas e necessárias transformações sociais, econômicas e políticas não apenas no Brasil, mas em todo o mundo capitalista. No ano de 1930 as forças populistas que assumiram o poder através de Getúlio Vargas, implementaram políticas econômicas que permitiram o contínuo crescimento econômico e a industrialização do País. Essas novas forças (ainda que de cunho oligárquicas) procuraram viabilizar um novo projeto de desenvolvimento para o País. Neste novo projeto, há uma inversão radical no padrão de acumulação de capital, que deixa de ser de caráter primário-exportador, cuja produção de valor se realizava externamente, para um acumulação de capital com base interna, ou seja, o mercado interno assume a preponderância, no que consiste à realização do valor da produção (OLIVEIRA, 1985).

Com o "deslocamento do centro dinâmico" da economia, o mercado interno assumiu função precípua no processo de desenvolvimento econômico (FURTADO, 1977). Este deslocamento do centro dinâmico possibilitou o início de uma nova fase de desenvolvimento que, segundo alguns autores, pode ser conceituada de "industrialização restringida" (MELLO, 1982).

A região Sudeste detinha a maior parte da indústria brasileira até 1950. Nessa primeira metade do século XX, a economia paulista concentrou estabelecimentos, emprego, renda e capital, de forma acelerada, devido as transformações ocorridas após o declínio da cultura da cana de açúcar, do algodão e do gado, produtos típicos da economia nordestina. Somente 0 Estado de São Paulo detinha $48 \%$ da indústria nacional, aumentando sua participação 
posteriormente para 58\% na década de 1960 (CANO, 1985). Este dado mostra que a economia paulista, detinha o poder de influenciar substancialmente o processo de reprodução do capital.

O Estado de São Paulo paulatinamente (desde o século XIX) concentrou um maior volume de indústrias em seu território, adquirindo um poder de barganha política relativamente grande. Oliveira (1985) mostra que:

O desenvolvimento industrial da "região" de São Paulo começou a definir, do ponto de vista regional, a divisão regional do trabalho na economia brasileira, ou mais rigorosamente, começou a forjar uma divisão regional do trabalho nacional, em substituição ao "arquipélago" de economias regionais até então existentes, determinadas sobretudo pelas suas relações com 0 exterior (OLIVEIRA, 1985, p. 53).

A crise mundial de 1929 possibilitou ao Brasil iniciar uma nova fase de desenvolvimento e industrialização (mesmo que restringida), permitindo ao Estado, superar, embora que parcialmente, ${ }^{7}$ "as formas oligárquicas e regionais de pressões e intervenção... [e procurar] ...os meios e caminhos para a centralização, para efetiva constituição de uma forma mais avançada de Estado Nacional, capitalista e burguês." (GUIMARÃES NETO, 1989, p. 93).

Com o Estado Novo, avança o processo de centralização burocrática, por meio da diversificação e complexidade do aparelho administrativo federal. Este novo Estado procura não apenas intensificar a industrialização, mas também promover intensivamente a integração do mercado nacional. Para Cano (1985, p. 185) "essa era, na verdade, nossa única opção para crescer e não estagnar."

Nesta procura intensa de industrialização e integração do mercado, o Estado ampliou consideravelmente sua intervenção direta e indireta na socioeconomia brasileira, procurando principalmente articular seus instrumentos de intervenção. Esta intervenção (direta e indireta) consubstanciou-se em diversas entidades, empresas públicas e mistas, órgãos de planejamento, políticas de incentivos etc. Dentre as principais pode-se citar: O Instituto do Açúcar e do Álcool (193l), do Cacau da Bahia (1931),do Mate (1938), do Pinho (1941), do Sal (1941); O Departamento Nacional de Produção Mineral (1934); do Conselho Nacional do Petróleo (1938), de Águas e Energia Elétrica (1939), de Minas e Metalurgia (1940); Companhia Siderúrgica Nacional (1941), a Vale do Rio Doce (1942), A Companhia Nacional de Alcalis (1943), a Fábrica Nacional de Motores (1943), a Companhia Hidrelétrica de São Francisco (1945), O Departamento Administrativo do Serviço Público (1938), o Ministério do Trabalho, Indústria e Comércio (1930), a Superintendência do Plano de Valorização Econômica da Amazônia (SPVEA) em 1953, etc.

\footnotetext{
7 Embora alguns autores preconizem a autonomia do Estado Novo superando as formas oligárquicas e regionais de pressão e intervenção, acreditamos que esta superação é parcial, pois as oligarquias continuam influenciando deterministicamente os destinos da economia nessas regiões periféricas.
} 
A quebra das barreiras alfandegárias, ${ }^{8}$ existente até 0 início da década de 40 , foi uma das medidas mais eficientes no processo de integração do mercado nacional. Porém, tanto a quebra das barreiras alfandegárias quanto os Institutos, Companhias e Conselhos, no que se refere à questão Nordeste, apenas aceleraram o crescimento das disparidades socioeconômicas e desigualdade regionais e o sobrepujamento da economia paulista sobre as demais. A intervenção do Estado no Nordeste, tinha caráter mais assistencialista, hídrico-emergencial (COHN, 1978), autoritário-paternalista (BURSZTYN, 1985), não possibilitando o declínio das disparidades socioeconômicas, principalmente entre a periferia (demais regiões, com exceção do Sul, que manteve certo grau de inserção com o Sudeste) e o Sudeste. Além do mais, com a quebra das barreiras alfandegárias as mercadorias produzidas pelo Sudeste, principalmente por São Paulo, puderam penetrar facilmente nas regiões periféricas, devido aos seus baixos preços, e qualidade superior as manufaturadas na periferia.

Como pode ser constatado na tabela 01 , e mais minuciosamente no trabalho de Wilson Cano (2008), as desigualdades regionais se aprofundaram até os anos 1970. São Paulo evolui em sua participação no PIB total de 31,2\% em 1939 para 39,5\% em 1970. Essa evolução ocorreu em detrimento do Nordeste, e de outras regiões. A partir de 1970 ocorre uma redução significativa nos diferenciais. São Paula apresenta redução na participação no PIB frente ao crescimento das demais regiões e unidades federativas.

Tabela 01

Participação Regional no PIB Total (Brasil = 100\%) 1939-2004

\begin{tabular}{lcccccccccc}
\hline & 1939 & 1949 & 1959 & 1970 & 1980 & 1985 & 1990 & 1995 & 2000 & 2004 \\
\hline $\mathrm{NO}^{*}$ & 2,6 & 1,7 & 2,0 & 2,2 & 3,2 & 4,1 & 4,7 & 4,6 & 4,6 & 5,2 \\
$\mathrm{NE}$ & 16,7 & 13,9 & 14,4 & 12,0 & 12,2 & 13,7 & 12,6 & 12,8 & 13,0 & 14,0 \\
$\mathrm{MG}$ & 10,0 & 10,4 & 7,9 & 8,3 & 9,4 & 9,7 & 8,9 & 9,7 & 9,7 & 9,4 \\
$\mathrm{ES}$ & 1,2 & 1,3 & 0,8 & 1,2 & 1,5 & 1,7 & 1,4 & 1,7 & 1,8 & 1,8 \\
$\mathrm{RJ}$ & 20,9 & 19,5 & 18,5 & 16,1 & 13,6 & 11,6 & 11,4 & 11,4 & 12,7 & 12,7 \\
$\mathrm{SP}$ & 31,2 & 36,4 & 37,9 & 39,5 & 37,7 & 35,8 & 35,3 & 35,5 & 33,3 & 31,1 \\
$\mathrm{PR}$ & 2,9 & 4,0 & 5,4 & 5,5 & 5,9 & 6,2 & 6,0 & 6,0 & 6,0 & 6,2 \\
$\mathrm{SC}$ & 2,2 & 2,5 & 2,4 & 2,8 & 3,3 & 3,3 & 3,4 & 3,6 & 3,8 & 4,0 \\
$\mathrm{RS}$ & 10,2 & 8,6 & 8,4 & 8,7 & 8,1 & 7,9 & 7,7 & 8,4 & 7,8 & 8,2 \\
CO* & 2,1 & 1,7 & 2,3 & 2,7 & 3,6 & 3,7 & 8,7 & 6,5 & 7,2 & 7,5 \\
DF & - & - & - & 1,0 & 1,5 & 2,3 & 5,4 & 2,7 & 3,0 & 2,5 \\
\hline
\end{tabular}

Fonte: FGV p/ 1939-1980; IBGE, Contas Regionais p/ 1985-2004 - IN: CANO, 2007

Quando se observa as diferenças regionais na renda média dos habitantes, os estados mais ricos, em especial Rio de Janeiro, São Paulo, Paraná, Rio Grande do Sul e o Distrito

\footnotetext{
8 Como os impostos alfandegários regionais se constituíam em "importante parcela da arrecadação fiscal de vários Estados, é compreensível que tenham permanecido até o final da década de 1930. Foram extintos a partir do exercício de 1938, com redução gradativa anual, tendo seu completo término em 1945 (CANO, 1985, p. 188)
} 
Federal apresentam as maiores diferenças em relação a média brasileira, em detrimento do Nordeste e do Norte.

Tabela 02

Diferenças regionais da renda média por habitante (Brasil $=100)$ - 1939-2004

\begin{tabular}{lllllll}
\hline & 1939 & 1970 & 1980 & 1990 & 2000 & 2004 \\
\hline NO(1) & 79 & 58 & 65 & 73 & 60 & 97 \\
$\mathrm{NE}$ & 33 & 40 & 42 & 44 & 47 & 51 \\
$\mathrm{MG}$ & 61 & 68 & 84 & 86 & 92 & 90 \\
$\mathrm{ES}$ & 62 & 71 & 87 & 94 & 107 & 106 \\
$\mathrm{RJ}$ & 239 & 166 & 143 & 124 & 148 & 150 \\
$\mathrm{SP}$ & 179 & 207 & 179 & 172 & 154 & 141 \\
$\mathrm{PR}$ & 96 & 75 & 92 & 109 & 106 & 110 \\
$\mathrm{SC}$ & 78 & 88 & 109 & 121 & 122 & 125 \\
$\mathrm{RS}$ & 127 & 122 & 123 & 130 & 129 & 137 \\
$\mathrm{CO}(1)$ & 69 & 55 & 67 & 81 & 75 & 87 \\
DF & - & 184 & 156 & 149 & 221 & 196 \\
\hline
\end{tabular}

Fonte: FGV/FIBGE - Censo Demográfico e Contas Nacionais. IN. CANO, 2007

CO(1) Exclui DF; inclui TO em 1939-1970. NO(1) Inclui TO a partir de 1990.

A elevação das rendas médias e da participação regional no PIB se constitui objetivo fundamental da República Federativa do Brasil. Compromisso assumido e positivado na Constituição Federal de 1988 (BRASIL, 1988), no seu artigo terceiro, incisos segundo e terceiro, que preconizam a garantia ao desenvolvimento nacional e a erradicação da pobreza, da marginalização e a redução das desigualdades sociais e regionais.

\section{A DESIGUALDADE REGIONAL, A INTERVENÇÃO ESTATAL E O ABANDONO DO PLANEJAMENTO}

Um dos grandes obstáculos ao processo de integração do mercado nacional, - a questão dos transportes, estradas e comunicações que intercomunicassem as regiões - foi superado gradualmente até a década de 70. Deve-se observar que, o processo de integração do mercado, é precedido a nível regional por uma integração ou articulação intraregional. Neste período, em que ocorre esta articulação intraregional, simultaneamente ocorre um grande desenvolvimento das estradas, transportes e comunicações, que possibilita em um momento posterior, a articulação inter-regional e a integração do mercado nacional. O Trabalho de Galvão consolida o pensamento de inúmeros estudiosos sobre o isolamento relativo das regiões brasileiras, afirmando que foi apenas com "a efetivação de um programa nacional de construção de rodovias 
nos anos 1950 e 1960, que o Brasil rompeu, de fato, o estado de relativo isolamento de suas economias regionais (GALVÃO, 1990, p. 02).

O Plano de Metas, implementado no Governo de Juscelino Kubitschek, além do aumento da produção de petróleo (meta para 1960, 308.000 barris/dia), investimentos em ferrovias (reaparelhamento e construção), rodovias (pavimentação de 5.800 km, e construção de $13.000 \mathrm{~km}) ; 9$ pretendia fomentar os serviços portuários e de dragagens, marinha mercante, transportes aeroviários, indústria automobilística, etc. (LAFER, 1987). Esses investimentos favoreceram a efetiva integração econômica das regiões brasileiras, como também promoveram abruptas mudanças na economia das regiões.

Ao ampliar-se consideravelmente o processo concorrencial entre as empresas, através do comércio inter-regional, possibilitou-se que determinadas regiões, principalmente o Estado de São Paulo ganhassem na competição do mercado. Muito embora Cano (1985, p. 191) preconize que "pode-se ganhar na competição de determinados produtos, mas não na de todos". Sabendo-se que o Estado de São Paulo já concentrava parcela importante da indústria do Brasil, e que sua agricultura despontava com grande produtividade e diversidade, não se pode deixar de concluir que, São Paulo tenderia a polarizar toda a economia do País. Evidentemente, o desenvolvimento dos transportes e comunicação, viria consolidar a hegemonia do Estado de São Paulo sobre as demais regiões.

O sistema de transportes e comunicações representou inicialmente uma barreira que obstaculizava a integração do mercado brasileiro. Representava uma barreira porque tantos os transportes como as comunicações eram ineficientes e insuficientes para o nível de desenvolvimento produtivo, que já se tinha alcançado no Brasil. Barreira esta que não foi eliminada instantaneamente. A ampliação das estradas de rodagens em conjunto com 0 desenvolvimento dos transportes e das comunicações, impulsionou a integração do mercado, favorecendo 0 sobrepujamento das mercadorias do Sudeste sobre as mercadorias manufaturadas nas regiões periféricas (CANO, 1985). Em outras palavras, podemos dizer que 0 fluxo (ou o comércio) de mercadorias entre o Sudeste e o Nordeste (e demais regiões) era superior ao fluxo Nordeste (periferia) para o Sudeste. Ou nas palavras do Grupo de Trabalho para o Desenvolvimento do Nordeste,

(...) o Centro-Sul vende no Nordeste quantidade substancialmente maior de mercadorias do que compra... Como as exportações do Centro-Sul para o Nordeste se compõem principalmente de manufaturas, pesando nas exportações nordestinas muito mais as matérias-primas, cabe concluir que a discrepância a favor do Centro-Sul ainda é maior se

\footnotetext{
9 Atingiu-se, porém, a meta de $6.202 \mathrm{~km}$ em 1960. Mais de $100 \%$ da quilometragem de estradas federais pavimentadas existentes até aquele momento. No que se refere a construção de estradas, atingiu-se a meta de $14.970 \mathrm{~km}$, ou seja, mais de $115 \%$ da meta prevista.
} 
se mede 0 intercâmbio em termos de massa de emprego criada nas duas regiões (GTDN, 1978, p. 28).

A crescente articulação comercial inter-regional (devido ao processo de integração do mercado nacional) proporcionou, segundo Cano, "efeitos de estímulo, de inibição ou bloqueio e, até mesmo, de destruição" (CANO, 1985, p. 191). Torna-se importante observar que o efeito de destruição ${ }^{10}$ deve-se a vários fatores, dos quais os principais são: a) a implantação das grandes indústrias automobilística; b) a construção dos grandes eixos rodoviários; c) ao avançado desenvolvimento do Estado de São Paulo, frente ao do Nordeste que contava com uma agricultura atrasada e minimamente diversificada; d) a uma indústria nordestina de baixa produtividade e estrutura pouco diversificada, e, e) ao agravamento da crise no setor exportador nordestino (salvo apenas o cacau).

A chamada "invasão" de mercadorias do Sudeste (São Paulo) sobre as demais regiões, em especial, o Nordeste provocou dois efeitos aparentemente contraditórios, que se mesclam continuamente. Assim um efeito de estímulo ocorreu no comércio através desta invasão, pois essas mercadorias chegavam ao Nordeste com preços baixos, devido à alta produtividade daquela região. Essas novas mercadorias possibilitaram o surgimento de novas empresas, que comercializavam com essas novas mercadorias, marginalizando as mercadorias próprias da região. Os estabelecimentos que vendiam exclusivamente mercadorias nordestinas (de baixa produtividade e altos preços) tenderam ao declínio, enquanto os estabelecimentos que inovaram, passaram a crescer, e ocupar maior espaço no mercado, como também absorveu nova e maior clientela.

O segundo efeito (de destruição) provocou o fechamento de estabelecimentos comerciais e indústrias. Porém, não se pode atribuir o encerramento das atividades produtivas ocorridos nas empresas nordestinas, apenas à invasão de mercadorias, pois a integração produtiva (entrada de novas empresas no mercado nordestino) fomentou consideravelmente 0 fim das empresas artesanais e de pequeno porte. Muito antes da fase de integração produtiva, a simples entrada (se é que podemos chamá-la de simples) de uma grande empresa no mercado nordestino, já provocava a destruição de muitos pequenos estabelecimentos industriais e/ou comerciais. Esta "invasão" de mercadorias, somente pode ser caracterizada como tal, após a década de 1940, quando as "barreiras alfandegárias" foram extintas, e os meios de transporte e

\footnotetext{
${ }^{10}$ Cano (1985) refere-se ao efeito de destruição, como se este efeito tivesse um impacto marginal. Ou seja, frente aos demais efeitos, não significam mesmo. Acredita-se que por isso Cano refere-se ao efeito de destruição como "até mesmo, de destruição...", demonstrando pouca importância aos efeitos destrutivos ocorridos neste período.
} 
rodovias estavam crescendo abruptamente, possibilitando a inserção de mercadorias do CentroSul no Nordeste com maior facilidade.

A articulação inter-regional promoveu intensas modificações na estrutura produtiva dos Estados. Essas modificações foram no "sentido de destruir atividades artesanais, caseiras ou das pequenas indústrias rurais" (GUIMARÃES NETO, 1989, p. 100). Assim, as unidades federativas nordestinas sofreram um declínio significativo em diversas atividades socioeconômicas, principalmente nas atividades que se caracterizavam por artesanais ou que utilizavam pequeno capital.

O fato supra, pode ser ratificado pelo estudo realizado por Martin Katzman, que mostra a existência de "um declínio significativo, em todos os Estados nordestinos, dos trabalhadores autônomos ou do autoemprego associado à atividade industrial, de acordo com dados dos censos demográficos" (GUIMARÃES NETO, 1989, p. 100).

Os dados apresentados por Pereira (1998) mostram que o Nordeste apresentou um baixo nível de comercialização inter-regional até a década de 1960. Os dados apresentados pelo mencionado autor devem ser apreciados com cautela, pois não trazem as cifras comercializadas por cabotagem, mas não deixam dúvida no que se refere à predominância que o comércio intraregional assume frente ao comércio inter-regional no Nordeste. Há de se observar que 0 mesmo acontece com o Sudeste, que a partir dos anos 1960 assume uma posição superavitária no comércio inter-regional com a periferia.

Os investimentos - públicos e privados - realizados no Nordeste não ampliaram apenas a sua capacidade produtiva e o poder de exportação, mas também suas importações, pois as indústrias instaladas nesta região caracterizavam-se por uma elevada dependência e complementaridade (ARAÚJO, 1984) para com as indústrias não regionais, principalmente para com o Estado de São Paulo.

Nos anos 1960 e 1970, o espaço econômico brasileiro passou por um processo de integração produtiva, ou mesmo inter-regionalização do espaço produtivo, no qual a industrialização dos espaços periféricos ao centro dinâmico teve papel fundamental e pode ser compreendido como o início da "dissolução das especificidades da reprodução do capital e da forma particular que a acumulação assume." (GUIMARÃES NETO, 1989, p. 123). Essa integração produtiva passa pela dissolução mencionada, que atinge o espaço econômico e político das regiões, provocando transformações quantitativas e qualitativas, que consolidam paulatinamente um sistema econômico integrado e hierarquizado, onde nova divisão do trabalho se estabelece nas microregiões que compõem o espaço econômico brasileiro. Esta nova divisão do trabalho traz em seu cerne um processo de desconcentração produtiva estimulada pelo 
Estado, desconcentração necessária para uma efetiva integração produtiva, mesmo que complementar e dependente (ARAÚJO, 1984).

Há um consenso entre estudiosos (CAIADO, 2002; PACHECO, 1998; DINIZ, 2000) que, entre 1970 e 1985, ocorreu no Brasil um processo de desconcentração produtiva, com a consequente redução das desigualdades regionais, como se vê nas tabelas 01 e 02 . Os estados de São Paulo e do Rio de Janeiro perderam, relativamente, participação na produção industrial e no PIB brasileiro. As respectivas áreas metropolitanas desses estados foram as que mais perderam participação relativa na produção industrial brasileira, devido ao processo de desconcentração e redução das desigualdades regionais. Essa desconcentração produtiva, denominada de reversão da polarização ${ }^{11}$, constituía-se de um processo que revertia à polarização do capital que se centralizava em São Paulo e, mais propriamente, na área metropolitana da capital do estado. No entanto, esse processo, tal qual se dava no período 1970/1985, foi amortecido, especialmente pelo afastamento do Estado, seu principal indutor.

As razões para o processo de desconcentração da economia brasileira, entre 1970 e 1985, devem-se a: i) deseconomias de aglomeração na área metropolitana de São Paulo, e criação de economias de aglomeração em outras regiões, ii) ação do Estado via investimento direto, incentivos fiscais e construção de infraestrutura, iii) busca de recursos naturais e consequente expansão agrícola; iv) efeitos locacionais da competição (DINIZ, 2000).

Nesse período, parte do capital, em especial o industrial, deslocou-se para as demais regiões do país. São Paulo, como principal centro produtivo-industrial foi o estado que mais perdeu com o processo de desconcentração. No período mencionado a participação de São Paulo na produção industrial nacional caiu de $58,2 \%$ para $51,9 \%$. Esse processo foi, no entanto, estancado a partir da segunda metade dos anos 1980, emergindo no final dos anos 1990, quando a participação do Estado no valor da transformação industrial alcançou 47,8\%, representando uma queda de mais de 4\% (CAIADO, 2002). $O$ fato do estado de São Paulo ter perdido participação na produção nacional não afetou a heterogeneidade de sua estrutura.

Quanto à Região Metropolitana de São Paulo, continua sendo o núcleo central da economia brasileira, embora o interior paulista já tenha superado a Região metropolitana como a maior concentração industrial do estado. Mas esse fato não anula o poder de atração desse espaço para as empresas de alta tecnologia. No ano de 2000 o município de São Paulo ainda continuava com a primazia no processo produtivo industrial brasileiro, participando com

\footnotetext{
11 O conceito reversão da polarização foi desenvolvido em: AZZONI, C. R. Indústria e reversão da polarização no Brasil. Ensaios econômicos. São Paulo: IPE/USP 1986. 0 termo polarização reversa se inspirou em um artigo de H. W. Richardson, de 1980, sobre a reversão da polarização ocorrida em diversos países que passaram por um processo de desindustrialização de algumas de suas cidades e regiões.
} 
aproximadamente $9,4 \%$. O processo de desconcentração da indústria, característica importante da reestruturação produtiva brasileira, não pode ser limitado, em sua explicação, às teorias neoclássicas de localização, devido à multiplicidade de dimensões e complexidade dos fatores envolvidos no processo. Dentro desse contexto multidimensional, destaca-se a atuação do Estado, em suas distintas esferas de ação (CAIADO, 2002).

O Rio de Janeiro, segunda maior área metropolitana e industrial do Brasil contemporâneo, similarmente a São Paulo, perdeu posição relativa na produção industrial brasileira. Diversos fenômenos contribuíram para o declínio relativo da participação fluminense e carioca na produção industrial do País. Dentre eles, merecem destaque: o declínio da agricultura do Estado, lastreada no café e na cana-de-açúcar; a transferência da capital para Brasília; a crise da indústria naval; as diversas crises políticas e sociais; mais recentemente, os impactos negativos do processo de privatização e de reforma do Estado e do crescimento do tráfico de drogas e do crime organizado. O Rio de Janeiro, que outrora participava com $38 \%$ na produção industrial brasileira, reduziu sua participação, em 1996, para 8\%. Do ponto de vista do Produto Interno Bruto, a participação do Estado é ainda de 11\% (DINIZ, 2000).

Não se pode falar em desindustrialização das áreas metropolitanas do Rio de Janeiro e de São Paulo devido ao contínuo crescimento de suas economias. No entanto, esse crescimento tem ficado aquém do crescimento de outras áreas, devido a inúmeros fatores, dos quais a relocalização de parte da indústria desses estados, as deseconomias de aglomeração e a guerra fiscal destacam-se. A configuração urbano-industrial que começou a delinear-se nos 1980 e 1990 apontava para a perda da importância e da participação no PIB das metrópoles nacionais São Paulo e Rio de Janeiro - em benefício das outras metrópoles nacionais e cidades de porte médio, principalmente as do centro-sul (DINIZ, 2000).

O desenho urbano-industrial e a sucinta desconcentração industrial dos anos 1990 diferem da ocorrida entre os anos 1970 e 1985, pois a desconcentração industrial, baseada na relocalização de inúmeros empreendimentos, deveu-se a fatores distintos daqueles que promoveram a desconcentração a partir da década de 1970. Ferreira e Lemos (2000) preconizam, como fator explicativo, para a localização de novas atividades industriais no espaço periférico, mais especificamente no Nordeste, o aproveitamento de potencialidades regionais para o desenvolvimento de indústria de base local.

Essa explicação cai por terra, quando os próprios autores mencionados afirmam que "(...) as políticas estaduais de desenvolvimento industrial ficaram resumidas à guerra fiscal entre as unidades da Federação (...)" (grifo nosso). Além disso, mostram que a busca por competitividade ocorre "(...) por meio da redução de seus custos com fatores, especialmente 
mão de obra barata que desencadearam o fenômeno de relocalização." (FERREIRA, 2000, p. 485). Relocalização resultante da guerra fiscal. Isso não significa que não seja possível o que os dois fenômenos atuem conjuntamente, no entanto, o fator principal para a relocalização dos empreendimentos deve-se aos incentivos fiscal-financeiros concedidos pelos estados da federação, na guerra fiscal que se deu nos anos 1990. O segundo fator refere-se à mão-de-obra barata que, nas regiões periféricas, é abundante, embora não qualificada. Para setores intensivos em mão-de-obra basta um mínimo de qualificação.

O Estado teve papel importante no processo de desconcentração produtiva no Brasil (1970-1985). Desde a década de 1960 que o Estado conduzia o processo de desconcentração. Esse processo tinha por finalidade tanto integrar 0 mercado nacional como promover 0 desenvolvimento das regiões que se encontravam à margem do desenvolvimento capitalista. Essas finalidades podem ser vistas através das políticas regionais desenvolvidas para 0 Nordeste a partir do fim dos anos 1950. No caso do Nordeste, o GTDN (1997) e a SUDENE defendiam uma política de desenvolvimento para a região tendo como carro-chefe a industrialização autônoma. Esta defesa se constituía em um discurso e em uma prática de intervenção direta e indireta no espaço urbano-industrial, tendo como um dos objetivos equalizar o desenvolvimento das regiões brasileiras atuando nas regiões menos desenvolvidas.

Em outras palavras, o Estado atuou fortemente, como produtor e como fomentador da industrialização, no desenvolvimento regional. Nesse contexto, o Estado agiu fortemente nas áreas urbanas como produtor direto através das estatais, nos polos petroquímicos, nas usinas, nas indústrias etc. Também concedeu inúmeros incentivos fiscais, através das superintendências de desenvolvimento das diversas regiões (SUDENE, SUDAM etc.) e, por fim, promoveu grande investimento na criação da infraestrutura básica para o capital e para a sociedade. Esta forte atuação do Estado ocorreu nos anos 1960 e com maior desenvoltura nos anos 1970.

A intervenção estatal contribuiu para a consolidação da urbanização, industrialização e metropolização de alguns espaços, quando aprovou e incentivou projetos, principalmente industriais, nas grandes cidades nordestinas. Salvador é um exemplo concreto de como um projeto industrial - o Complexo Petroquímico de Camaçari (COPEC) - instalado na periferia, beneficiou toda a região metropolitana (SOUZA, 2004). Fortaleza também muito beneficiou-se com a ação da SUDENE e do BNB, cuja matriz sedia. O processo de intervenção do Estado nos anos 1970 definiu o perfil de muitas cidades brasileiras e, em especial, das metrópoles (MELO, 1995).

A crise petrolífera, a inflação e o crescente déficit na balança de pagamento nos anos 1970 provocaram uma gradual contenção nas intervenções do Estado, principalmente das 
intervenções diretas e infraestruturas. Se o Plano de Ação Econômica do Governo propunha 0 grande investimento em infraestrutura e como tal foi relativamente realizado, o I PND e o II PND refletiram a crise que se previa a partir da desvalorização do dólar e do primeiro choque do petróleo. As contenções dos investimentos infraestruturas foram realizadas minimamente, devido à opção do endividamento por parte do Governo Federal (MELO, 1995). As crises políticas, econômicas e fiscais dos anos 1970 gradualmente minaram a atuação direta do Estado no espaço urbano industrial. Essas crises afetaram a capacidade de investimento do Estado, principalmente no que se refere à infraestrutura produtiva, fator preponderante na atividade econômica e no desenvolvimento regional.

A recessão brasileira do início da década de 1980 levou o país à forte crise econômica, na qual o Estado, negligenciando em suas funções básicas (investimentos em saúde, educação, segurança etc.), transferiu recursos para o pagamento da dívida externa. Esta situação calamitosa fomentou, no início da década (1981-1983), o declínio do PIB brasileiro, retornando aos níveis da década de 1970 apenas em 1985. A crise brasileira reflete-se principalmente nos espaços urbanos e industriais. A pressão exercida pelos bancos credores foi intensa e contou com o apoio dos respectivos governos dos países devedores. Essa pressão caracterizou-se pela exigência (aos países devedores) do ajustamento econômico, realizado nos termos predeterminados pelo FMl e pelos bancos internacionais.

O ajustamento, feito pelo Brasil no fim dos anos 1970, provocou o declínio no PIB nos anos 1981 e 1983 (-4,4\% e -3,3\% respectivamente) como também prejudicou imensamente os investimentos infraestruturas. O Governo Figueiredo esqueceu assim, o projeto políticoeconômico, pretensamente objetivado no início de governo (através do III PND) e passou a administrar a crise, gastando as reservas internacionais e usando o crédito externo possível de ser obtido (empréstimos para pagar dívidas anteriores). As atividades do Governo Federal são sobrepujadas pela administração da crise econômica (PEREIRA, 1994).

A crise é administrada e todas as atenções governamentais voltam-se para a balança de pagamento, em especial a balança comercial, e o serviço da dívida. Na segunda metade dos anos 1980, as intervenções do Governo Federal foram na direção do reordenamento da economia através do controle do processo inflacionário. Assim, lançou-se mão de planos de estabilização de caráter predominantemente heterodoxos, para acabar, através do choque, com a inércia inflacionária. Os planos mais importantes no período foram: o plano Cruzado (1986), 0 Plano Bresser (1987) e o Plano Verão (1989). Nesse período, a inflação tornou-se o objetivo central da política do governo federal. 


\section{GUERRA FISCAL COMO RESPOSTA (IN)ADEQUADA A DESIGUALDADE REGIONAL}

A guerra fiscal, ocorrida após os anos 1980, apresentou-se como se inexorável fosse, e como se o Nordeste brasileiro atuasse como principal fomentar do conflito. Diversos trabalhos (BNDES, 2000; SIMÕES, 2003, etc.) mostraram que o Nordeste não foi a principal região a promover o conflito, quando se analisa a participação dos municípios, mas midiaticamente se apresentava como a de maior relevância.

Some-se a guerra fiscal as intensas transformações nas estruturas produtivas dos estabelecimentos industriais. Estas transformações colaboraram para a acentuação da guerra fiscal. Essas transformações foram denominadas, nos anos 1990, de reestruturação produtiva, que por meio da renovação tecnológica, garantiu a determinados segmentos elevada flexibilidade nas condições de produção e gestão organizacional, elevou a possibilidade de mobilidade desse empreendimento, favorecendo, assim, que ao término do incentivo, as empresas se deslocassem para outra localidade que concedesse novos incentivos (ALVES, 2000).

Na década de 1990, na busca por investimentos privados, os estados utilizaram seis benefícios fiscais relacionados ao ICMS (ALVES, 2000): a) isenção do ICMS para novas empresas sem produto similar no estado e durante determinado período; b) isenção ou redução do ICMS pra as micros e pequenas empresas; c) redução de alíquotas de ICMS (para situações e produtos específicos); d) prorrogação dos prazos de recolhimento do ICMS; e) utilização dos mecanismos de diferimento (recolhimento postergado do ICMS); e, f) utilização do crédito presumido (por estimativa do ICMS).

Esses mecanismos, somente com raras exceções, não foram utilizados pelos estados no Brasil. Alguns estados, como a Bahia e a Paraíba, utilizaram quase todos simultaneamente. Outros tipos de benefícios não relacionados ao ICMS também foram utilizados destacando-se os estímulos para infraestrutura (venda de lotes e galpões, locação de máquinas e equipamentos, doação de áreas etc.), as concessões financeiras (aquisição de ativos fixos, composição acionária etc.) e ainda incentivos como a simplificação do processo de registro de empresas, a assistência técnica na elaboração de projetos, os programas de formação e capacitação etc. (BNDES, 2000).

Nesse contexto de conflito federativo, alguns estados deram ênfase às questões tecnológicas na concessão dos incentivos, destacando-se a Bahia, Goiás, Minas Gerais, o Paraná, o Rio de Janeiro e São Paulo. Notadamente, nesse grupo, encontram-se os estados de 
maiores economias da federação. Há uma concordância entre os diversos estudiosos da questão de que os benefícios fiscais e creditícios se anulam, e deixam de contribuir como fatores de decisão locacional por se tratar dos mesmos instrumentos de incentivo (BRITO, 1997).

No Nordeste, todos os estados, uns mais do que outros, participaram da guerra fiscal. Os estados do Ceará, de Pernambuco e da Bahia se destacaram pelo esforço agressivo em atrair novos investimentos através dos incentivos fiscais e financeiros. No entanto, esse esforço não logrou pleno efeito e incremento significativo no valor da transformação industrial desses estados, a exceção da Bahia (PEREIRA, 2008).

A análise das despesas com a rubrica desenvolvimento regional nos anos 1990 e 2000 permite a constatação de que os estados que mais investiram no desenvolvimento regional foram a Bahia e Pernambuco. Esse investimento trouxe, porém, mais benefícios ao primeiro Estado do que ao segundo (PEREIRA, 2008).

A intervenção do Estado, via competição fiscal e extrafiscal, no espaço urbano industrial se constitui como reflexo de um novo contexto socioeconômico e político, em que o capital em seu processo de acumulação apresenta características de elevada flexibilidade, e o Estado se apresenta em uma crise fiscal profunda. No Brasil um paradoxo se reflete no fato de o Estado se encontrar em crise fiscal profunda, com todos os entes federativos apresentando elevada dívida pública, ao mesmo tempo, que concedem incentivos fiscais. Esse fato somente se justifica pela crença dos gestores do setor público de que a renúncia fiscal traria benefícios superiores às perdas. No curto prazo, até é possível a existência de ganhos (emprego e renda para população), mas no médio e longo prazo, a possibilidade de mobilidade desses empreendimentos anula os ganhos de curto prazo (BNDES, 2000).

Diversas cidades ganhadoras, espaços urbanos em que os empreendimentos se localizam, perderam empreendimentos que se relocalizaram com 0 intuito de manter os incentivos fiscais (BENKO, 1999). Normalmente essas relocalizações ocorrem quando os incentivos fiscais estão perto de seu prazo de extinção, ou pouco tempo após o fim dos mesmos.

As políticas municipais de desenvolvimento industrial acompanharam as estaduais, acentuando a guerra fiscal entre as cidades e as unidades da Federação, utilizando-se do pequeno poder fiscal que Ihes cabia. As renúncias fiscais advogadas como "investimentos" por parte das concedentes deterioraram as condições financeiras, já fragilizadas pelo endividamento, dos estados e municípios. Alguns municípios, principalmente os próximos às grandes regiões metropolitanas, ganharam postos de trabalho, reflexo dos investimentos realizados pelo capital que se realocou. 
Municípios de todas as regiões brasileiras participaram da guerra fiscal, acentuando os incentivos e a guerra já vivenciada pelos estados. No trabalho de Simões (2003) é possível constatar a distribuição, por regiões, do percentual de municípios que contribuíram com a guerra fiscal através da criação de incentivos para atração de novas empresas. A região Sul foi a que apresentou a maior proporção de municípios com incentivos (78,7\%). O Nordeste, no entanto, apresentou apenas $39,7 \%$ dos municípios com tal política de incentivos. A região Sudeste apresentava um percentual pouco superior a $57 \%$ devido em grande parte à participação de Minas Gerais que apresentou aproximadamente $46 \%$ dos municípios com incentivos, puxando a participação da região para baixo, pois é o estado com o maior número de municípios no Brasil (853).

Minas Gerais é um caso interessante por existir uma polaridade socioeconômica, na qual o norte do estado em muito se aproxima das características do nordeste brasileiro (semiárido) e - Sul aproximar-se das características do Sudeste. As regiões Norte e Centro-Oeste apresentaram um percentual de municípios com incentivos elevados, 54,1\% e 61,3\% respectivamente, o primeiro com valores abaixo da média nacional e o último acima (SIMÕES, 2003).

Nos dados apresentados por Simões (2003) é possível observar as disparidades proporcionais existentes entre os estados brasileiros, no que consiste a participação dos municípios na guerra fiscal. O referido autor põe por terra todo o discurso de que o Nordeste tem apresentado substanciais incentivos promovendo a relocação das empresas do Sul e Sudeste. Os estados com o maior número relativo de municípios integrando a guerra fiscal via concessão de incentivos fiscais e extrafiscais são os do Sul e do Sudeste, a exceção do estado do Acre. Dos cinco primeiros Estados com maior participação, quatro são do Sul e Sudeste, enquanto, dos dez com menor participação, sete são do Nordeste.

A diversidade desses incentivos é significativa. No caso dos municípios nordestinos encontramos como principais incentivos a doação de terras seguida da isenção do ISS e do IPTU. Como pode ser visto nos trabalhos de Simões (2003), a região Sul apresentou proporcionalmente a existência de incentivos à implantação de novas empresas. No entanto, os percentuais dos incentivos vinculados ao fornecimento de infraestrutura e doação de terra são os mais elevados enquanto os percentuais dos incentivos fiscais e financeiros ficam um pouco abaixo dos concedidos pelos municípios nordestinos.

A guerra fiscal cria conflitos na federação. No curto prazo, o Estado que detona a guerra fiscal, normalmente é quem se beneficia. No longo prazo, a generalização do conflito faz com que os resultados iniciais desapareçam. Incentivos fiscais perdem seu pouco poder de 
estímulo e transformam-se em meras renúncias de arrecadação. Devido a homogeneização potencial dos benefícios fiscais e extrafiscais, no longo prazo as empresas passam a eleger sua localização somente em função das condições estruturais de mercado e de produção. Condições estas que incluem a qualidade da infraestrutura e dos serviços públicos oferecidos e o nível de qualificação da mão-de-obra (BNDES, 2000).

Os poucos ganhos da guerra fiscal provocaram uma transformação dos setores econômicos, que se pode entender como uma reconfiguração produtiva (PEREIRA, 2008) provocada em primeira instância pela reestruturação produtiva do capital, secundariamente, as políticas públicas - econômicas, urbanas etc. - nos anos 1990 e 2000, em especial, os projetos de desenvolvimento estaduais que são fundamentados na guerra fiscal.

A reconfiguração urbano-industrial das cidades resultante da confluência da ação inovativa das empresas e da ação do estado, promoveu consideravelmente a concentração e centralização econômica, favorecendo alguns estados em detrimento dos demais, ampliando a desigualdade intraregional e regional. Além disso, importa ressaltar que parte desse processo foi e ainda é promovido pela ação inconstitucional das unidades federativas, pois a guerra fiscal tal qual foi realizada atenta diretamente contra a Constituição Federal de 1988, em particular contra os princípios da ordem econômica plasmada na mencionada Carta Magna (ALMEIDA, 2010).

\section{CONSIDERAÇÕES FINAIS}

Em um passado não muito distante, o federalismo brasileiro caracterizou-se por uma concentração excessiva no poder central. Desde o início da década dos 1980 o Brasil ingressou em um processo de mudanças institucionais, que se acentuou na década dos 1990.

O regime federalista brasileiro encontra-se em processo de mutação, com a transferência de responsabilidades da união para os estados e municípios. Nesse período, a elevação de responsabilidade sem o mesmo volume de transferência de recursos levou as unidades federativas, mesmo sem consenso entre os estados ou autorização dos organismos responsáveis, a promover incentivos fiscais-financeiros como forma de atrair empreendimentos econômicos e favorecer o crescimento de emprego e renda. Esse procedimento realizado pelas unidades federativas estabeleceu uma guerra fiscal que distante de promover o desenvolvimento econômico e a redução dos desequilíbrios econômicos e regionais, terminou por amplificá-los.

A guerra fiscal beneficiou alguns estados em detrimento de outros, ratificando a concentração econômica e a desigualdade regional dentro da própria região e sem reduzir essa 
mesma desigualdade social e regional no País. A guerra fiscal favoreceu muito mais as unidades federativas mais ricas e maiores dentro do Nordeste em detrimento das demais unidades.

Em busca do desenvolvimento econômico acentuam-se os desequilíbrios, as desigualdades e as atividades não sustentáveis. Ratifica-se muito mais um crescimento econômico não sustentável do que um processo de desenvolvimento econômico sustentável.

Alterar esse processo é fundamental para o desenvolvimento econômico sustentável. Pois a continuidade das desigualdades sociais e regionais demostra a insustentabilidade do processo. A persecução dos princípios e diretrizes econômicas constitucionais se torna um imperativo para o desenvolvimento econômico sustentável brasileiro. Nesse sentido, a extinção da guerra fiscal, via desabilitação da concessão de incentivos fiscais e financeiros concedidos a revelia de qualquer programa nacional de desenvolvimento integrado, torna-se procedimento relevante e pertinente.

\section{REFERÊNCIAS BIBLIOGRÁFICAS}

ALMEIDA, Rogério C. Incentivos fiscais e extrafiscalidade: intervenção estatal em busca de desenvolvimento econômico e a guerra fiscal entre os Estados. Dissertação de Mestrado em Direito. Recife, UFPE. 2010

ALTHUSSER, Louis. Aparelhos Ideológicos de Estado. Rio de Janeiro: Graal, 1985

ALVES, Giovanni. 0 novo (e precário) mundo do trabalho. reestruturação produtiva e crise no sindicalismo. São Paulo: Boitempo, 2000.

ARAÚJO. Tânia B. de. Industrialização do Nordeste: Intenções e Resultados IN: A questão Nordeste. MARANHÃO, Silvio et alli. ed. Paz e Terra - São Paulo - 1984

AZZONI, C. R. Indústria e reversão da polarização no Brasil. Ensaios econômicos. São Paulo: IPE/USP 1986

BANCO NACIONAL DE DESENVOLVIMENTO ECONÔMICO E SOCIAL (BNDES). Guerra fiscal: competição tributária ou corrida ao fundo do tacho? Informe-se. Secretaria de Assuntos Fiscais. BNDES/BNDESPAR, n. 04, janeiro de 2000

BENKO, G. A Ciência Regional, Portugal, Oeiras: Celta 1999

BERCOVICl, Gilberto. Desigualdades regionais, Estado e Constituição. São Paulo: Max Limonad, 2003,

BOBBIO, Noberto. O marxismo e o Estado, Rio de Janeiro: Graal 1979.

BRASIL. Constituição Federal do Brasil. Senado Federal, Brasília, 1988

BRITO, Adriana Fernandes; BONELLI, Regis. Políticas industriais descentralizadas: as experiências europeias e as iniciativas subnacionais no Brasil. In. Planejamento e Políticas públicas. V. 01, n. 01, Brasília, jun. de 1997

BURSZTYN, Marcel. O Poder dos Donos. Petrópolis - RJ - Ed. Vozes 1985

CAIADO, Aurilio Sergio Costa. Reestruturação Produtiva e Localização Industrial: a dinâmica Industrial na RMSP entre 1985 e 2000. mimeo. ANPEC. 2002

CANO, Wilson. Desequilíbrios Regionais e Concentração Industrial no Brasil.1930 - 1970 ed. Global São Paulo 1985

CANO, Wilson. Desconcentração produtiva regional do Brasil 1970-2005. 3. ed. rev. e ampl. São Paulo: Unesp, 2008

CARNOY, Martin. Estado e Teoria Política. São Paulo: Papirus, 1994. 
COHN, Amélia. Crise Regional e Planejamento. São Paulo - $2^{0}$ ed.- ed. Perspectiva S.A. 1978 DINIZ, Clélio C. Impactos Territoriais da reestruturação produtiva. In: RIBEIRO, Luiz César de Queiroz. 0 Futuro das Metrópoles: desigualdades e governabilidade. Observatório, UFRJFASE, Rio de Janeiro: Revan, 2000

ENGELS, Frederich. Origem da família, da propriedade privada e do Estado. IN: MARX, Karl; ENGELS, Frederich. Obras Escolhidas. Vol. I, II e III. São Paulo: Alfa-Omega 1980.

FARIAS, Flávio Bezerra. 0 Estado Capitalista Contemporâneo. São Paulo: Cortez, série Questões da Nossa Época, n. 73, 2000.

FERREIRA, Maria de Fátima S. \& LEMOS, Mauro B. Localização Industrial e Fatos Estilizados da Nova Reconfiguração Espacial no Nordeste. IN: Revista Econômica do Nordeste. Vol.31, N. Especial, Fortaleza, nov. de 2000

FURTADO, C. Nova Concepção Federalismo do IN: O Longo Amanhecer: Reflexões sobre a Formação do Brasil, Rio de Janeiro, Paz e Terra, 1999,

FURTADO, Celso. Formação Econômica do Brasil. 15a edição. Ed. Companhia Editora Nacional. São Paulo 1977

GALVÃO, Olímpio de Arroxelas. Comércio Interregional e Integração dos Mercados no Brasil. 1945 - 1969. mimeo. Pimes, UFPE - Recife - PE 199

GTDN. Uma Política de Desenvolvimento Econômico para o Nordeste. SUDENE. RECIFE, 1978

GUIMARÃES NETO, Leonardo. Introdução à Formação Econômica do Nordeste. Recife - PE - Ed. Massagana 1989

HARVEY, D. A Produção Capitalista do Espaço. São Paulo: Annablume, 2005, p. 86

LAFER, Betty mindlin. Planejamento no Brasil._5a edição. Ed. Perspectiva - São Paulo - Serie Debates. 1987

LOJKINE, Jean. A análise marxista do Estado. IN: Espaço e Debates, número 01, ano 01, São Paulo, 1981.

MARX, Karl. Contribuição à crítica da economia política. São Paulo: Martins Fontes. 1983. O capital, Crítica da economia política. São Paulo: 1988

MELLO. João Cardoso de. 0 Capitalismo Tardio ed. Brasiliense. São Paulo - 1982

MELO, Marcus A. B. C. de. Globalização, Crise do Estado e Metrópoles no Brasil. IN: GONÇALVES, Maria Flora (org). O Novo Brasil Urbano: impasses, dilemas, perspectivas. Porto Alegre: Mercado Aberto 1995

MILIBAND, Ralph. 0 Estado e a Sociedade Capitalista. Rio de Janeiro: Zahar, 1972 MINÓN, Miguel Herrero de. Territorios históricos y fragmentos do estado. Revista Española de Derecho Constitucional. Año 5. Núm. 14. Mayo-agosto 1985

OLIVEIRA, Francisco de. Elegia para uma Re(li)gião. 4a ed. ed. Paz e Terra - Rio de Janeiro 1985

PEREIRA, William E. N., Intervenção do Setor Público no Nordeste. Monografia de graduação em Economia - Universidade Federal da Paraíba - Campus II , atual UFCG - 1994

PEREIRA, W. E. P. A Evolução Econômica de Campina Grande: Uma Avaliação da Economia Municipal a partir do Comércio. Dissertação de Mestrado em Economia. Universidade Federal da Paraíba. 1998

PEREIRA, W. E. N. Reestruturação do Setor Industrial e Transformação do Espaço Urbano de Campina Grande -PB a partir dos anos 1990. Tese (Doutorado em Ciências Sociais). Universidade Federal do Rio Grande do Norte (UFRN), 2008

SIMÕES, André. Descentralização Federativa e "Desenvolvimento" Fragmentado: uma análise dos incentivos a atração de atividades econômicas nos municípios das regiões Sul e Nordeste. Recife. V Encontro de Economistas de Língua Portuguesa - 5 a 7 de novembro de 2003

SOUZA, Celina. Regiões Metropolitanas: Trajetória e influência das escolhas institucionais. IN: RIBEIRO, Luiz César de Q. (org.) Metrópoles: entre a coesão e a fragmentação, a cooperação e o conflito. São 
Paulo: ed. Fundação Perseu Abramo, Rio de Janeiro: FASE - Federação de Órgãos para Assistência Social e Educacional, 2004.

\section{Recebido para avaliação em Janeiro de 2020. Aceito para Publicação em Maio de 2020.}

\section{RESUMO}

O desenvolvimento brasileiro foi marcado pela desigualdade social e regional. Mas não deve ficar reduzido ao bem-estar de alguns poucos grupos ou agentes. Para evitar a continuidade desse estado de coisas, a ação estatal é fundamental. Mas não uma ação qualquer e sim, uma ação deliberadamente estimuladora do desenvolvimento sustentável. 0 objetivo central é analisar sucintamente alguns pontos do processo de desenvolvimento desigual no Brasil e 0 papel da guerra fiscal na redução da desigualdade regional. A hipótese é que a guerra fiscal não contribui para a redução das desigualdades fiscais. A pesquisa histórico-dedutiva e a revisão bibliográfica se constituíram em atividades permanentes no decurso da elaboração desse paper. Um outro passo fundamental se constituiu em um levantamento de dados secundários que possibilitem a fundamentação das ideias desenvolvidas. Os resultados encontrados demonstram que a guerra fiscal não soluciona o desenvolvimento desigual.

PALAVRAS CHAVE: Estado, Região, Desenvolvimento, Desigualdades.

\section{ABSTRACT}

Brazilian development was marked by social and regional inequality. But it must not be reduced to the welfare of a few groups or agents. To avoid continuing this state of affairs, state action is essential. But not just any action, but an action that deliberately stimulates sustainable development. The central objective is to briefly analyze some points of the process of unequal development in Brazil and the role of the fiscal war in reducing regional inequality. The hypothesis is that the fiscal war does not contribute to the reduction of fiscal inequalities. Historical-deductive research and bibliographic review became permanent activities in the course of preparing this paper. Another fundamental step was a survey of secondary data that enable the foundation of the ideas developed. The results found demonstrate that the fiscal war does not solve uneven development.

WORDS KEY: State, Region, Development, Inequalities 